\title{
Research on Simulation Evaluation of Goods Out-stock Capability of Strategic Projection Base
}

\author{
Fubing Peng ${ }^{1, a, *}$, Zhenke $\mathrm{Li}^{1, \mathrm{~b}}$ and Weizhong Zhang ${ }^{1, \mathrm{c}}$ \\ 1Joint Projection Department, Military Transportation University, Tianjin 300161, China; \\ apengfubing1982@163.com, bjjxylzk@126.com, cwillson_zwz@163.com
}

\begin{abstract}
Keywords: Strategic Projection Base, Goods Out-stock Capability, Simulation Evaluation.
Abstract. By analyzing goods out-stock operating process of Strategic Projection Base, this paper created a simulation model based on Extend simulation platform. Take a certain material support task for example, according to run the simulation model and analyze the output, it verified the reliability and applicability of the model, tested and evaluated the out-stock capability, found out the job 'bottleneck', put forward the suggestions on improving the out-stock capability, and provided the basis for optimizing the allocation of resources.
\end{abstract}

\section{Introduction}

Strategic projection base is a new type of projection support force, which based on transport hubs, using modern transportation and logistics technology, integrated functions include the formed units projection and goods transport. It is an important basis of strategic projection [1] 。 The first strategic projection base has completed construction. It's an urgent job to evaluate whether its operation capability can complete support task, whether the operation equipments configuration is scientific and reasonable, and whether the operation efficiency can achieve the optimal.

Goods out-stock capability refers to goods out-stock quantity in a certain time after receiving material transport task, which is an important index of material transport capability. By analysing the operation process of goods out-stock, the paper created a graphical simulation model based on Extend. Then according to running a specific support task instance, it tested the out-stock capability of completing the task, found out the key influent factors, and put forward some countermeasures for optimizing the operation efficiency. It provided scientific basis for optimizing operation links and equipments configuration, and promoting the development of strategic projection bases.

\section{The operation process of goods out-stock}

Goods out-stock operation system is constituted of out-stock operation facilities and related personnel. Its operation process was shown in figure 1, which mainly included out-stock operation of four warehouses. Four warehouses included automated cargo station of No.I and No.II plane freight station of No.III, underground station of No.IV. After receiving out-stock instructions, the pre-storage 180 pallets of the ULD automated station (located in station No. II) outbound firstly, and can be finished in one and a half hours. Resource allocation model allocated the difference between the total out-stock task quota and the pre-storage quantity to four freight stations, and each station completed its out-stock task by itself.

The out-stock process of Station No.I,II,IV were similar. When accepted out-stock tasks, they took out the goods shelves. If the tasks were beyond their gruoping capability, took the part in excess to Station No.III. Or the goods would be took to security check. Goods qualified security would be transported to group board machine for manual unpacking and grouping. The pallets grouped continued to undergo size detection, weighing, printing labels and labeling line. Then the pallets in Station No.I,IV would be took to check the weight. The pallets in Station No.II would be took to platform by power conveyor, sent to the outbound power conveyor by TV, and carried to weight check. Qualified pallets transported to apron, and the unqualified would take back to group. 
Station No.III itself didn't stored goods. Its task was to group goods transferred from Station No.I,II,IV. Goods transferred would be carried to the platform of Station No.III, and moved to security check by electric forklifts. Then they would undergo manual unpacking, grouping, size detection, weighing, printing labels, labeling line, and be transported to apron after weight check.

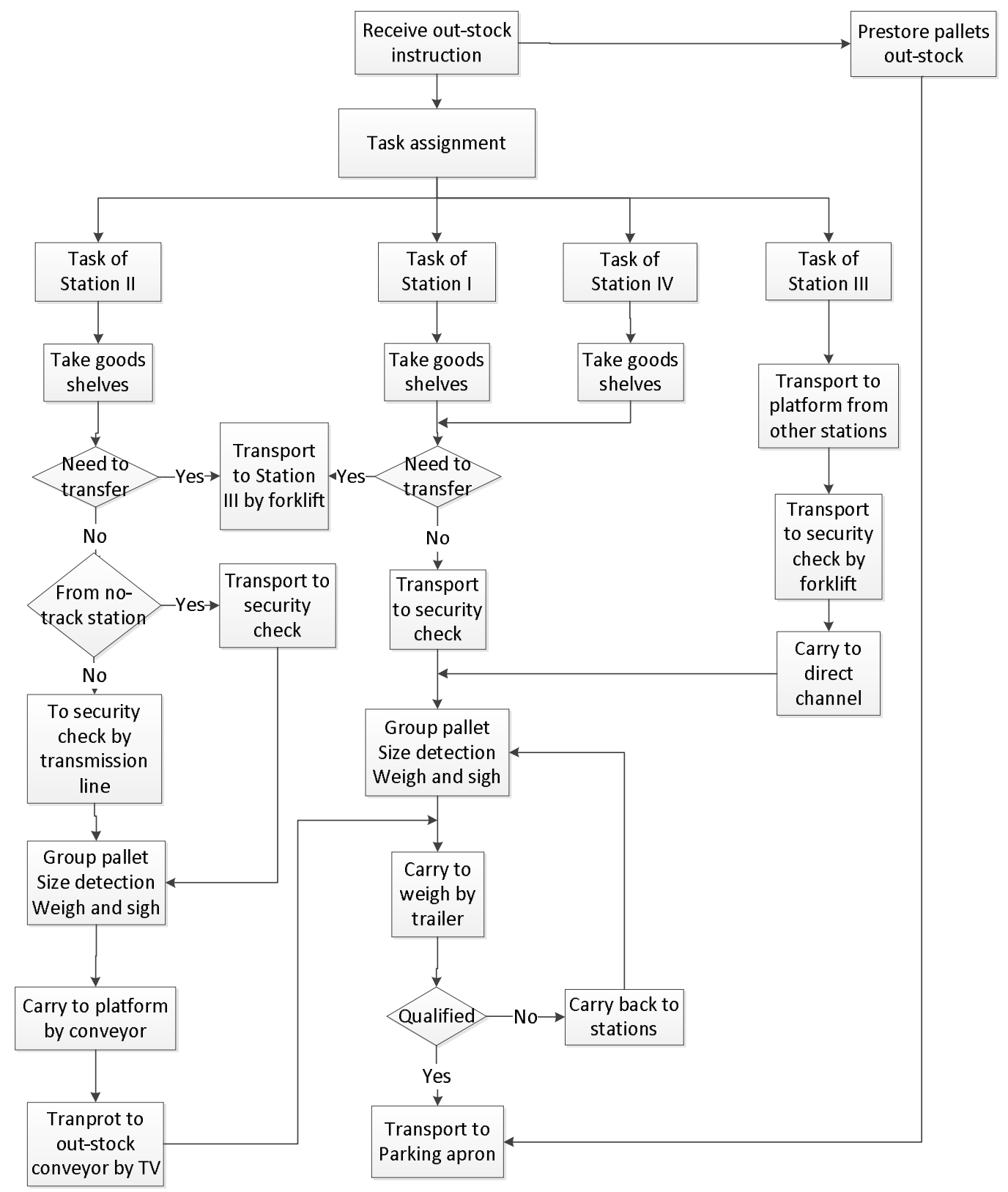

Fig. 1 The operation process of goods out-stock

\section{Simulation modeling of goods out-stock based on Extend}

The Extend is a visual simulation software developed by Imagine That company in United States, which has the characteristics of high flexibility and extensibility, easy to learn, easy to human-computer interaction. It is widely applied in many fields such as logistics, transportation, manufacturing, and so on.[2] Reference [3] provided methods of building warehouses' operation simulation models of strategic projection base based on Extend. On this basis, this paper integrated simulation models according to out-stock operation process, constructed out-stock simulation model, determined the form of input and output parameters, and provided the calculation method of the simulation running times. 
Based on operation process of goods out-stock, the out-stock simulation model was be established, as shown in Figure 2.

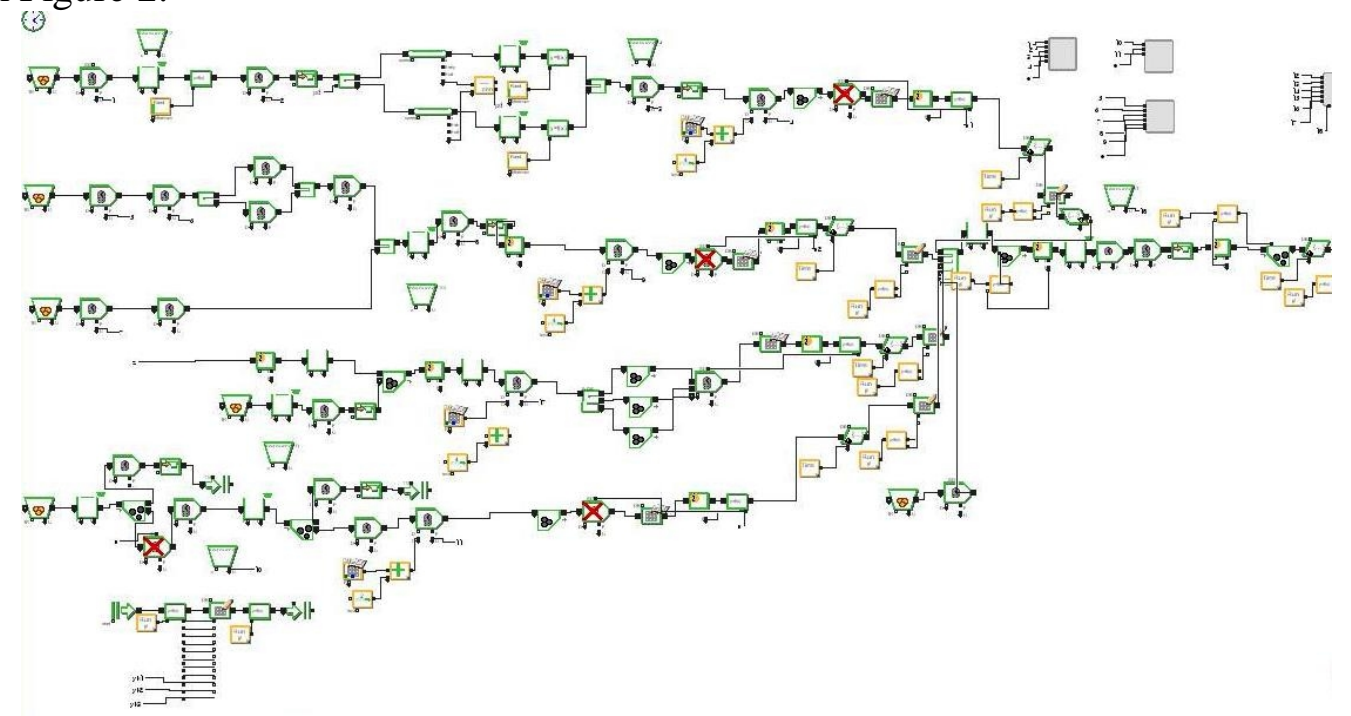

Fig. 2 The out-stock simulation model

\section{Input parameters}

The input parameters of the model consisted of manual operation parameters, machine operation parameters, manual cooperate with machine operation parameters, and various parameters of out-stock quantity.

Manual operation included manual unpacking and manual grouping. By the means of field measurements, the dismantling time of each tray was about 6 seconds. Grouping time related to the material types, the quilt of which was 30 minutes, camping equipment and sanitary equipment of which was about 26 minutes, food and medicine of which was about 33 minutes.

Machine operation included size detection, weight, printing labels, security, stacker machine operation, the shuttle plate and TV transport operation. Their operational time parameters could be confirmed by means of field measurement or calculation. The average time of size detection, weight, printing labels was 6 seconds; the security check time of each tray was 40 seconds; the operation time of stacker machine subjected to uniform distribution for 125-137 seconds; similarly the time of shuttle plate was for 55 - 75 seconds, and the time of TV car was for 95 -135 seconds.

Manual cooperate with machine operation included work of electric forklift, high forklift, trailer and truck. The operation time related to transportation distance. The speed of them was respectively $4 \mathrm{~m} / \mathrm{s}$, $3 \mathrm{~m} / \mathrm{s}, 5 \mathrm{~m} / \mathrm{s}$ and $6 \mathrm{~m} / \mathrm{s}$. The operation time could be calculated according to the travel.

\section{Output parameters}

Output parameters described grouping task quota, transferring task quota (had been converted into quantity of planets) of every station, and the time to complete the task. They also concluded the workload of main equipments, by which we could find out 'bottleneck' restricting the out-stock capability and improve it.

\section{The simulation running times}

The simulation running times could be confirmed by approximate calculation. Firstly it ran ' $\mathrm{N}_{0}$ ' times according to the actual situation (e.g., 10 times). The initial sample variance 's' could be calculated. Then the total times ' $\mathrm{N}$ ' could be calculated according to the following formula.

$$
\mathrm{N}=\left[\left(\mathrm{Z}_{\mathrm{c} / 2}\right) \times \mathrm{s}+\mathrm{h}\right]^{2}
$$

In this formula, ' $\alpha$ ' was significance level, usually took the value of 0.05 . ' $Z_{\alpha / 2}$ ' was the critical point at ' $\alpha / 2$ ' of standard normal distribution. ' $h$ ' was a half wide of the confidence interval, namely the absolute error. If the results did not meet the requirements of error (i.e., absolute error was less than $5 \%$ ), increased the running times until met the error requirement. 


\section{Model verification and example analysis}

To test and verify the rationality and validity of simulation model, find out the weak links and optimize the operation process, we needed to take specific support task for instance. By running the simulation model, it would analyze the output, find the key influent factors, and make further improvement and perfection of the model.

\section{The task scenarios}

Assuming that in the summer of 20XX, it rains heavily in the south, and occurrs severe floods in the Yangtze river basin. People in the disaster area are in urgent need of relief supplies. Affected by the flood, the ground transportation damage is bigger, and lots of supplies pile up in the surrounding area and can't reach. To support people's life, treat and cure the wounded and patients timely, the superior department commands strategic projection base transport supplies to the disaster areas by air as soon as possible. It's urgent request that the base complete out-stock task within four hours.

\section{The input parameters}

Various material out-stock task parameters were given concluded the out-stock quantity of four categories such as quilt, camping equipment, sanitary equipment, food and drug (had been converted into quantity of planets), and also concluded the quantity of ULD prestored.

Airlift supplies totaled 1245 tons and 420 pallets. Among them, there were 130 tons of food and drugs (equivalent to 30 pallets), 336 tons of quilt (equivalent to 150 pallets), 230 tons of sanitary equipment (equivalent to 100 pallets), 549 tons of camping equipment (equivalent to 140 pallets).

The ULD automated warehouse prestored the quilt, sanitary equipment and camping equipment, the number were 80 pallets, 50 pallets and 50 pallets. The input parameters were as shown in figure 3 .

\begin{tabular}{|c|c|c|c|}
\hline & A & B & C \\
\hline 1 & tydes of materials & out-stock task & prestore quantity \\
\hline 2 & quilt & 150 & 80 \\
\hline 3 & $\operatorname{san} i \operatorname{tar} y$ & 100 & 50 \\
\hline 4 & camping equipment & 140 & 50 \\
\hline 5 & food, drug & 30 & 0 \\
\hline 6 & & 420 & \\
\hline
\end{tabular}

\section{The results of simulation output}

Fig.3 The input parameters

The output variables of the model mainly included the completion time of overall task and of each station. The absolute error was set to $5 \%$, then the simulation running times were 2 according to the formula (1). Run simulation model and the output as shown in figure 4, figure 5. Figure 4 showed the grouping task and grouping time. Figure 5 showed the workload of equipment.

\begin{tabular}{|c|c|c|c|c|c|c|c|c|c|}
\hline & A & B & $\mathrm{C}$ & D & E & $\mathrm{F}$ & G & $\mathrm{H}$ & I \\
\hline 1 & station & $\begin{array}{l}\text { group } \\
\text { pallet } \\
\text { task }\end{array}$ & $\begin{array}{l}\operatorname{tranfer} \\
\text { task }\end{array}$ & $\begin{array}{l}\text { number of } \\
\text { simulation }\end{array}$ & $\begin{array}{l}\text { overall } \\
\text { finish } \\
\text { time }\end{array}$ & $\begin{array}{l}\text { finish time } \\
\text { of Station } \\
\text { I }\end{array}$ & $\begin{array}{l}\text { finish time } \\
\text { of Station } \\
\text { II }\end{array}$ & $\begin{array}{l}\text { finish time } \\
\text { of Station } \\
\text { III }\end{array}$ & $\begin{array}{l}\text { finish time } \\
\text { of Station } \\
\text { IV }\end{array}$ \\
\hline 3 & II & 48 & 92 & 2 & 228. 667min & 163.096 & 161. 003 & 166.029 & 197.667 \\
\hline 4 & III & 112 & 0 & & & & & & \\
\hline 5 & IV & 30 & 0 & & & & & & \\
\hline
\end{tabular}

Fig 4 Grouping task and grouping time of each station

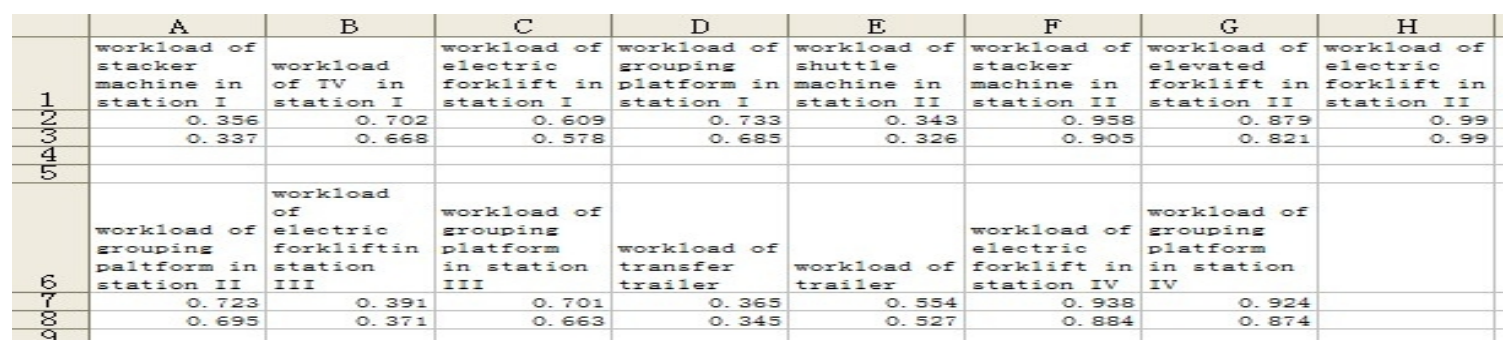

Fig 5 Workload of equipment 


\section{The analysis of simulation results and optimization}

Figure 4 showed that the average task completion time was 227.3 minutes, and the base could finish out-stock task of 1245 tons of supplies within four hours, which met the demand of material support task. The grouping task of station No.I,II,III,IV. were 50,48,112,30 pallets. The transferring task of station No.I,II were 20 and 92 pallets, the sum of which was the grouping task of station No.III. The grouping capability of station No.IV could meet the demand and not need to transfer.Through twice simulation running, the average time of task completion of four stations were 163.7 minutes, 158.7 minutes, 166 minutes and 197.8 minutes.

Figure 5 showed that the workload of electric forklift and stacker machine of station No.II were higher, which became the operation 'bottleneck'. Main reason lied in that the sanitary equipment and camping equipment were stored in station No.II out-stock task was heavier. Meantime the quantity of electric forklifts and stacker machine was not enough.

In addition, the time of task completion of station No.IV was significantly more than other. The reason was that the quantity of grouping platform was less, and the workload of that was higher than other three stations.

The following measures could be taken to optimize the system and improve the efficiency. For example, we could increase the quantity of electric forklifts and reduce the workload, in order to improve the grouping capability of station No.III. We could increase the quantity of stacker machine and improve the operational efficiency, so as to improve the utilization rate of the shuttle plate. We could also increase the quantity of grouping platform of station No.IV and improve the grouping capability, so as to reduce the operation completion time.

\section{Conclusion}

Taken the goods out-stock capability of strategic projection base as the object, this paper put forward a simulation modeling method based on Extend simulation platform. According to the operation process of goods out-stock, it built simulation model, determined the form of input and output parameters, and provided the calculation method of the simulation running times. Through the analysis of support task instance, it tested and evaluated operational capability of the base, verified the reliability and applicability of the model, found out the job 'bottleneck', gave the suggestions on improving the out-stock capability, and provided a theoretical basis for optimizing the construction and plan of strategic projection base.

\section{References}

[1] Fubing Peng, Zhaoren Chen. Pengfei Guo.etc:Research On States and Development Mechanism of Army-Civilian Integrated Emergent Projection Support System.Journal of Military Transportation University. Vol.15(2013), p. 9-12

[2]Tianbao Qing, Yanfeng Wang: Application Oriented Simulation Modeling and Analysis with ExtendSim (Second Edition), Tshighua University Press, BJ (2011), p. 5-6.

[3]Fubing Peng, Erdun E, Tenglong Cui, Research on Simulation Evaluation of Strategic Projection Base Construction Plan in ExtendSim Environment.Applied Mechanics and Materials Vol.641-642(2014), p. 704-710. 